\title{
ARMAZENAMENTO E GERMINAÇÃO DE SEMENTES DE TABEBUIA AUREA (MANSO) BENTH. \& HOOK. F. EX. S. MOORE ${ }^{1}$
}

\author{
Edna Lopes Cabral ${ }^{2}$ \\ Dilosa Carvalho de Alencar Barbosa ${ }^{2}$ \\ Eliana Akie Simabukuro ${ }^{2}$
}

\section{Recebido em 25/09/2002. Aceito am 04/06/2003}

\begin{abstract}
RESUMO - (Armazenamento e germinação de sementes de Tabebuia aurea (Manso) Benth. \& Hook. f. ex. S. Moore). As sementes foram acondicionadas em sacos de papel, de algodão e plástico de natureza permeável, em ambiente frio e seco $\left(15^{\circ} \mathrm{C}\right.$ e $40 \%$ de UR) por quatro meses. Inicialmente, testou-se a influência da presença e ausência contínua de luz branca e fotoperíodo de $12 \mathrm{~h}$, a fim de determinar o fotoblastismo das sementes, na temperatura de $25^{\circ} \mathrm{C}$. Verificou-se a influência das temperaturas constantes de $10,15,20,25,30,35$ e $40^{\circ} \mathrm{C}$ na germinação e determinou-se as temperaturas cardeais (mínima, ótima e máxima). Testou-se a viabilidade das sementes aos 60, 90 e 120 dias de armazenamento, empregando-se teste de germinação, e a velocidade de embebição aos 30, 60 e 90 dias, utilizando-se amostras provenientes de cada tipo de embalagem. As embalagens utilizadas no armazenamento não afetaram significativamente as variáveis estudadas. A espécie em estudo pode ser classificada como fotoblástica neutra à $25^{\circ} \mathrm{C}$, com percentagem média de germinação alta, variando de 88 a $98 \%$. A temperatura ótima de germinação foi de $35^{\circ} \mathrm{C}$, a mínima de $20^{\circ} \mathrm{C}$ e a máxima de $40^{\circ} \mathrm{C}$, na ausência de luz. As embalagens utilizadas no armazenamento mantiveram a viabilidade das sementes por até 120 dias, com altos percentuais de germinação, variando de 88 a 97\%. As sementes apresentaram velocidade de embebição rápida atingindo $100 \%$ a partir das quatro horas de embebição.
\end{abstract}

Palavras-chave - Tabebuia aurea, germinação, luz, temperaturas cardeais, longevidade

\begin{abstract}
Storage and germination of seeds of Tabebuia aurea (Manso) Benth. \& Hook. f. ex. S. Moore). The seeds were conditioned in paper, cotton and permeable plastic bags, in cold and dry environment $\left(15^{\circ} \mathrm{C}\right.$ and $40 \% \mathrm{RU}$ ) for four months. Initially, was tested the influence of the presence and absence continuos of white light and photoperiod of $12 \mathrm{~h}$ at $25^{\circ} \mathrm{C}$. The effect of constant temperatures $\left(10,15,20,25,30,35\right.$, and $\left.40^{\circ} \mathrm{C}\right)$ on germination was evaluated and cardinal temperatures were determined (minimum, optimum and maximum). Viability of the seeds was evaluated through germination tests at 60, 90, and 120 days. Imbibition velocity tests were
\end{abstract}

\footnotetext{
Parte da Dissertação de Mestrado da primeira Autora, financiada pela CAPES

2 Departamento de Botânica, Universidade Federal de Pernambuco, Av. Prof. Moraes Rego s/n, Cidade Universitária, CEP 50560-901, Recife, PE, Brasil (ednacabral2002@yahoo.com.br; dilosa@ufpe.br)
} 
carried out using samples proceeding from each storage package, at 30, 60, and 90 days. The storage packages utilized had no significant effect on the studied variables. The species studied was classified as neutral photoblastic at $25^{\circ} \mathrm{C}$, with a high average germination percentage, varying from 88 to $98 \%$. Optimal germination temperature was of $35^{\circ} \mathrm{C}$, with a minimum at $20^{\circ} \mathrm{C}$ and a maximum at $40^{\circ} \mathrm{C}$, in the absence of light. The utilized storage packages extended the viability of the seeds up to 120 days, with high germination percentages, varying from 88 to $97 \%$. The seeds showed accelerated velocity of imbibition, reaching $100 \%$ from four hours of imbibition exposure on.

Key words - Tabebuia aurea, germination, light, cardinal temperatures, longevity

\section{Introdução}

A Caatinga, ecorregião semi-árida única no mundo, é provavelmente o bioma brasileiro mais ameaçado e transformado pela ação humana. Além de ser exclusivamente brasileira, a Caatinga cobre porção significativa do território nacional, $11,67 \%$, a se considerar as áreas de transição para outros biomas (Casteleti et al. 2003). Torna-se urgente a compreensão dos processos de regeneração neste ambiente para fins de reposição vegetal e conservação da biodiversidade.

Tabebuia aurea (Manso) Benth. \& Hook. f. ex S. Moore é uma espécie arbórea da família Bignoniaceae, conhecida vulgarmente como craibeira, caraibeira ou para-tudo. Ocorre nas margens de rios temporários do Nordeste semiárido, integrando também a flora dos Cerrados e Cerradões de quase todo o Brasil. Possui fruto do tipo folículo, com sementes dotadas de alas, dispersas pelo vento. É planta de múltiplas utilidades, tendo sua madeira de textura mediana, aplicação em vigamentos, esquadrias, móveis, cabos de ferramentas, construção civil e serviços diversos. Presta-se ainda para a arborização de ruas e praças pela abundância de floração vistosa e pela sombra que pode proporcionar. Apresenta rápido crescimento, podendo ser indicada para reflorestamento, principalmente em matas ciliares, nas regiões de baixa pluviosidade (Lorenzi 1992).

A germinação de sementes é processo complexo e depende de diversos fatores, como temperatura, luz, água e composição de gases na atmosfera (Mayer \& Poljakoff-Mayber 1979; Popinigis 1985; Carvalho \& Nakagawa
1988; Kigel \& Galili 1995).

O efeito da temperatura sobre a germinação tem especial importância para a ecologia de populações. Para os esporos e sementes serem capazes de germinar, suas "temperaturas cardeais" devem corresponder às condições externas que assegurem desenvolvimento suficientemente rápido para as plantas jovens (Larcher 2000). Quanto maior a faixa de temperatura, mais ampla é a distribuição geográfica da espécie em estudo (Labouriau 1983).

Estudos sobre a influência da temperatura na germinação das sementes são essenciais para entender os aspectos ecofisiológicos e bioquímicos desse processo (Labouriau 1983; Bewley \& Black 1994). Seus efeitos podem ser avaliados a partir de mudanças ocasionadas na percentagem, velocidade e frequiência relativa de germinação ao longo do tempo de incubação (Labouriau \& Pacheco 1978).

A faixa de temperatura ótima é aquela onde acontece a germinabilidade máxima, registrando-se o percentual mais alto de germinação, no menor tempo médio (Labouriau 1983).

Muitas espécies cultivadas são indiferentes à luz para germinar, entretanto, o estímulo luminoso é bastante variável em sementes de várias espécies selvagens (Mayer \& PoljakoffMayber 1979), havendo espécies cujas sementes são afetadas positiva ou negativamente, e sementes que não são afetadas pela luz (Viana \& Felippe 1986).

A conservação das sementes, de modo geral, é de grande importância, uma vez que tem função básica de preservar a qualidade fisiológica das mesmas, sendo essa preservação possível 
porque o armazenamento uma vez aplicado de modo adequado, vai diminuir a velocidade de deterioração, que se caracteriza por ser processo irreversível (Delouche et al. 1973; Melo et al. 1998).

As sementes de espécies do gênero Tabebuia possuem período de viabilidade relativamente curto, o que representa dificuldades no estabelecimento de técnicas de cultivo para silvicultura e reflorestamento de áreas degradadas, além de limitar sua dispersão natural (Pinto et al. 1986).

A fase de germinação tem início com a embebição da água, reidratando as sementes e ativando o metabolismo do tecido embrionário (Mayer \& Poljakoff-Mayber 1979; Popinigis 1985; Melo et al. 1998; Larcher 2000). A velocidade da absorção da água pela semente varia com a espécie, permeabilidade do tegumento, disponibilidade de água, temperatura, pressão hidrostática, área de contato semente/ água, forças intermoleculares, composição química e condição fisiológica (Mayer \& Poljakoff-Mayber 1979; Popinigis 1985).

Estudos dos processos fisiológicos da semente são efetivamente o ponto de partida para utilização e exploração de forma racional das espécies nativas, especialmente da Caatinga, cujos trabalhos sobre germinação ainda são escassos, destacando-se as publicações de Tigre (1970), Souza et al. (1980a, b), Barros \& Barbosa (1991), Queiroz (1999) e Nascimento \& Oliveira (1999).

No presente trabalho é descrito o efeito da luz e da temperatura na germinação e do armazenamento na viabilidade das sementes de Tabebuia aurea, bem como a velocidade de embebição ao longo do período de armazenamento.

\section{Material e métodos}

Os experimentos foram conduzidos no laboratório de Fisiologia Vegetal do Departamento de Botânica da Universidade Federal de Pernambuco. Foram utilizadas sementes da espécie Tabebuia aurea coletadas em novembro/2000, de uma população natural ocorrente em área de Caatinga hiperxerófila, Fazenda Brejo, Município de Canindé do São Francisco (9³0' e $10^{\circ} 00^{\prime}$ S e $37^{\circ} 30^{\prime}$ e $38^{\circ} 00^{\prime} \mathrm{W}$ ), Sergipe.

Após a coleta, as sementes foram colocadas para secar ao ar livre por 15 dias, em seguida acondicionadas em sacos de papel Kraft, algodão e plástico transparente permeável, em câmara fria e seca $\left(15^{\circ} \mathrm{C}\right.$ e $40 \%$ de UR), pertencente a Empresa Pernambucana de Pesquisa Agropecuária (IPA), durante quatro meses, para serem utilizadas nos ensaios de germinação. O grau de umidade das sementes foi determinado ao início e ao final do período de armazenamento, pelo método de estufa a $105^{\circ} \mathrm{C}$, descrito nas Regras para Análise de Sementes (Brasil 1992), utilizando-se quatro repetições de 10 sementes, para cada tipo de embalagem utilizada.

Para os testes de germinação, foram utilizadas placas de Petri de $9 \mathrm{~cm}$ diâm., devidamente esterilizadas, forradas com duas folhas de papel de filtro umedecido com $8 \mathrm{~mL}$ de água destilada. Amostras constituídas por 10 repetições de 10 sementes, para cada tipo de embalagem de armazenamento, foram mantidas em câmaras de germinação do tipo B.O.D, marca FANEM. As sementes foram consideradas germinadas quando apresentaram comprimento radicular maior ou igual a $2 \mathrm{~mm}$. Os testes foram encerrados quando todas as sementes já haviam germinado ou quando as remanescentes se apresentavam deterioradas (aproximadamente vinte dias) nas placas. As observações foram diárias e sempre ao mesmo horário. Em todos os ensaios as sementes foram utilizadas com as alas.

Efeito da luz - Os testes foram realizados em temperatura constante de $25^{\circ} \mathrm{C}\left( \pm 2^{\circ} \mathrm{C}\right)$, na presença e ausência de luz contínua e fotoperíodo de $12 \mathrm{~h}$. A ausência de luz foi obtida pelo envolvimento das placas de Petri em dois 
sacos de polietileno preto e as contagens foram efetuadas sob luz verde de segurança (Labouriau 1983). A luminosidade das câmaras de germinação foi de cerca de $4 \mathrm{Wm}^{-2}$. Utilizaramse sementes com um mês de armazenamento, provenientes dos diferentes tipos de embalagens.

Efeito da temperatura - A fim de se determinar as temperaturas ótima, máxima e mínima de germinação, foi avaliada a influência das seguintes temperaturas constantes: 10,15 , $20,25,30,35$ e $40^{\circ} \mathrm{C}$. Foram utilizadas sementes com dois meses de armazenamento nas condições descritas anteriormente. Os ensaios foram realizados na ausência de luz.

Efeito do tempo e do tipo de embalagem no armazenamento - De acordo com os melhores resultados nos testes de luz e temperatura foi verificada a viabilidade das sementes em função do tempo e do tipo de embalagem, realizando-se os testes de germinação a $35^{\circ} \mathrm{C}$ e ausência de luz aos 60, 90 e 120 dias de armazenamento.

Efeito do tempo e do tipo de embalagem de armazenamento na embebição - A velocidade de embebição foi observada nas sementes armazenadas por 30, 60 e 120 dias. Foram utilizadas quatro amostras com dez sementes, provenientes de cada tipo de embalagem citada anteriormente. As amostras foram pesadas individualmente (peso inicial) em balança analítica com precissão de $0,0001 \mathrm{~g}$, colocadas dentro de béqueres contendo $50 \mathrm{~mL}$ de água destilada, e mantidas por $12 \mathrm{~h}$ em condições de laboratório $\left(25 \pm 2^{\circ} \mathrm{C}\right.$ e $68 \pm 3 \%$ de UR). Foram realizadas pesagens a cada duas horas, durante o tempo de embebição, sendo as sementes retiradas da água, secas em lenços de papel, pesadas e novamente colocadas na água. Ao final do período de $12 \mathrm{~h}$ de embebição, as amostras foram transferidas para estufa a $105 \pm$ $2^{\circ} \mathrm{C}$, por $24 \mathrm{~h}$, com a finalidade de se determinar o peso da matéria seca das amostras.

Análise dos dados - Os cálculos de percentagem, tempo médio, velocidade média de germinação foram obtidos através das fórmulas citadas em Labouriau (1983) e Labouriau \& Valadares (1976) e a percentagem de embebição segundo Popiningis (1985). O delineamento experimental foi inteiramente casualizado. Para as análises estatísticas os dados de percentagem de germinação foram transformados em arc sen $\sqrt{\%}$. Os dados foram submetidos a análise de variância e as médias comparadas pelo teste $t a$ 5\% de probabilidade, utilizando-se o programa BIOESTAT (Ayres \& Ayres Júnior 1998).

\section{Resultados e discussão}

Efeito da luz - Diferenças significativas não foram observadas na germinabilidade das sementes de Tabebuia aurea armazenadas em diferentes embalagens e submetidas aos tratamentos fotoblásticos (Tab. 1). O percentual médio de germinação a $25^{\circ} \mathrm{C}$ na ausência de luz variou de 88 a 98\%, nas embalagens de plástico e papel, respectivamente. Na presença de luz, a variação foi de 90 a $97 \%$ nas embalagens de plástico e algodão, sendo portanto, fotoblásticas neutras.

Segundo Bewley \& Black (1994), a sensibilidade das sementes à luz varia com a espécie e em função da temperatura utilizada no processo de germinação. Felippe \& Silva (1984) comentam que grande número de espécies que ocorrem no cerrado são indiferentes à luz. Exemplos podem ser citados com as espécies: Dipteryx alata Vog., nas temperaturas constantes de $16^{\circ} \mathrm{C}, 33^{\circ} \mathrm{C}$ e $40^{\circ} \mathrm{C}$ (Melhem 1975); Rapanea guianensis Aubl., Magonia pubescens St. Hil. e Camponanesia pubescens (D.C.) Berg. à $25^{\circ} \mathrm{C}$ (Joly \& Felippe 1979; Joly et al. 1980; ArrigoniBlank et al. 1997) e Stylosanthes macrocephala M.B. Ferr. \& Sousa Costa de $10^{\circ} \mathrm{C}$ a $40^{\circ} \mathrm{C}$ (Silva \& Felippe 1986). Na caatinga, Barbosa (1980) verificou que as sementes de Anadenanthera macrocarpa (Benth.) Brenan, também são indiferentes à luz à $25^{\circ} \mathrm{C}$.

O tempo médio de germinação não diferiu entre os tratamentos na embalagem de papel. 
Tabela 1. Germinação, tempo médio e velocidade média de germinação na presença e ausência de luz contínua e fotoperíodo de $12 \mathrm{~h}$ à $25^{\circ} \mathrm{C} \mathrm{em}$ sementes de Tabebuia aurea (Manso) Benth. \& Hook. f. ex. S. Moore, armazenadas por um mês em câmara fria e seca $\left(15^{\circ} \mathrm{C} ; 40 \%\right.$ U.R.), em sacos de papel, algodão e plástico.

\begin{tabular}{llccc}
\hline Tipo de embalagem & Tratamento & $\begin{array}{c}\text { Germinação } \\
(\%)\end{array}$ & $\begin{array}{c}\text { Tempo médio } \\
(\text { dias })\end{array}$ & $\begin{array}{c}\text { Velocidade média } \\
\left(\mathrm{d}^{-1}\right)\end{array}$ \\
\hline \multirow{2}{*}{ Papel } & Presença de luz & $94 \mathrm{a}$ & $2,84 \mathrm{a}$ & $0,36 \mathrm{a}$ \\
& Ausência de luz & $98 \mathrm{a}$ & $2,60 \mathrm{a}$ & $0,39 \mathrm{a}$ \\
& Fotoperíodo & $97 \mathrm{a}$ & $2,64 \mathrm{a}$ & $0,38 \mathrm{a}$ \\
Algodão & Presença de luz & $97 \mathrm{a}$ & $2,83 \mathrm{a}$ & $0,36 \mathrm{a}$ \\
& Ausência de luz & $95 \mathrm{a}$ & $2,48 \mathrm{~b}$ & $0,41 \mathrm{a}$ \\
& Fotoperíodo & $91 \mathrm{a}$ & $2,59 \mathrm{~b}$ & $0,39 \mathrm{a}$ \\
\multirow{3}{*}{ Plástico } & Presença de luz & $90 \mathrm{a}$ & $3,26 \mathrm{a}$ & $0,31 \mathrm{~b}$ \\
& Ausência de luz & $88 \mathrm{a}$ & $2,44 \mathrm{~b}$ & $0,41 \mathrm{a}$ \\
& Fotoperíodo & $89 \mathrm{a}$ & $2,59 \mathrm{~b}$ & $0,39 \mathrm{a}$ \\
\hline
\end{tabular}

* Médias seguidas de mesma letra não diferem entre si ao nível de 5\% de significância

Nas embalagens de algodão e plástico houve redução significativa nos tratamentos mantidos na ausência de luz e fotoperíodo de $12 \mathrm{~h}$.

Em relação aos valores de velocidade média de germinação, não foram evidenciadas diferenças significativas entre os tratamentos fotoblásticos, com exceção apenas para o tratamento sob luz contínua para as sementes acondicionadas em saco plástico, que apresentaram o menor valor $\left(0,31 \mathrm{~d}^{-1}\right)$. Embora não havendo diferenças significativas, o tratamento na ausência de luz apresentou os maiores valores absolutos de velocidade média em todos os tipos de embalagens.

Efeito da temperatura - Nas temperaturas constantes de $10^{\circ} \mathrm{Ce} 15^{\circ} \mathrm{C}$, não houve germinação nos diferentes tipos de embalagens. Nestas condições, observou-se suscetibilidade das sementes ao ataque de fungos e a deterioração das mesmas a partir do oitavo dia (Tab. 2).

A faixa de temperatura entre $20^{\circ} \mathrm{C}$ e $40^{\circ} \mathrm{C}$ mostrou-se favorável à germinação, com percentagens médias acima de $80 \%$. Resultados semelhantes foram verificados por Barbosa (1980), ao estudar a germinação das sementes de Anadenanthera macrocarpa, cujos valores de germinação situaram-se entre $98 \%$ a $100 \%$, após 48h de semeadas, em condições amostrais de laboratório.

Quanto ao percentual de germinação, não houve diferença significativa entre as temperaturas constantes de $30^{\circ}$ e $35^{\circ} \mathrm{C}$. No entanto, à $35^{\circ} \mathrm{C}$ a velocidade média de germinação se mostrou estatisticamente superior para as sementes acondicionadas em sacos de papel, algodão e plástico, com valores de 0,50, 0,49 e $0,49 \mathrm{~d}^{-1}$, respectivamente. Esta temperatura, portanto pode ser considerada como ótima para germinação de T. aurea, uma vez que apresentou alta taxa de germinação em menor tempo médio. A temperatura mínima foi de $20^{\circ} \mathrm{C}$ e a máxima acima de $40^{\circ} \mathrm{C}$, na ausência de luz. De tudo que foi exposto, verificou-se que as sementes de T. aurea germinaram dentro de ampla faixa de temperatura. Essa característica significa caráter adaptativo que propicia alta capacidade de estabelecimento em campo, aumentando assim a chance de sobrevivência, em comparação com as espécies que apresentam estreita faixa de temperatura para germinar (Townsend \& MacGinnies 1972; Labouriau 1983).

Efeito do tempo e do tipo de embalagem no armazenamento - $\mathrm{O}$ teor de água das sementes 
Tabela 2. Germinação, tempo médio e velocidade média de germinação em sementes de Tabebuia aurea (Manso) Benth. \& Hook. f. ex. S. Moore, em diferentes regimes de temperatura, na ausência de luz, armazenadas em câmara fria e seca $\left(15^{\circ} \mathrm{C} ; 40 \%\right.$ U.R $)$, por dois meses, em sacos de papel, algodão e plástico.

\begin{tabular}{ccccc}
\hline $\begin{array}{c}\text { Temperatura } \\
\left({ }^{\circ} \mathrm{C}\right)\end{array}$ & Tipo de embalagem & $\begin{array}{c}\text { Germinação } \\
(\%)\end{array}$ & $\begin{array}{c}\text { Tempo médio } \\
(\text { dias })\end{array}$ & $\begin{array}{c}\text { Velocidade média } \\
\left(\mathrm{d}^{-1}\right)\end{array}$ \\
\hline \multirow{2}{*}{20} & Papel & $92 \mathrm{~B} \mathrm{a}$ & $6,51 \mathrm{~A} \mathrm{~b}$ & $0,15 \mathrm{D} \mathrm{a}$ \\
& Algodão & $88 \mathrm{~B} \mathrm{a}$ & $7,06 \mathrm{~A} \mathrm{a}$ & $0,14 \mathrm{D} \mathrm{b}$ \\
& Plástico & $85 \mathrm{~B} \mathrm{a}$ & $7,13 \mathrm{~A} \mathrm{a}$ & $0,14 \mathrm{D} \mathrm{b}$ \\
25 & Papel & $98 \mathrm{AB} \mathrm{a}$ & $2,61 \mathrm{~B} \mathrm{a}$ & $0,39 \mathrm{C} \mathrm{a}$ \\
& Algodão & $95 \mathrm{~A} \mathrm{a}$ & $2,48 \mathrm{C} \mathrm{a}$ & $0,41 \mathrm{~B} \mathrm{a}$ \\
& Plástico & $88 \mathrm{~B} \mathrm{~b}$ & $2,44 \mathrm{C} \mathrm{a}$ & $0,41 \mathrm{BC} \mathrm{a}$ \\
30 & Papel & $99 \mathrm{~A} \mathrm{a}$ & $2,33 \mathrm{C} \mathrm{a}$ & $0,43 \mathrm{~B} \mathrm{a}$ \\
& Algodão & $96 \mathrm{~A} \mathrm{a}$ & $2,38 \mathrm{C} \mathrm{a}$ & $0,42 \mathrm{~B} \mathrm{a}$ \\
35 & Plástico & $99 \mathrm{~A} \mathrm{a}$ & $2,30 \mathrm{C} \mathrm{a}$ & $0,44 \mathrm{~B} \mathrm{a}$ \\
& Papel & $97 \mathrm{AB} \mathrm{a}$ & $2,03 \mathrm{D} \mathrm{a}$ & $0,50 \mathrm{~A} \mathrm{a}$ \\
& Algodão & $97 \mathrm{~A} \mathrm{a}$ & $2,05 \mathrm{D} \mathrm{a}$ & $0,49 \mathrm{~A} \mathrm{a}$ \\
40 & Plástico & $97 \mathrm{~A} \mathrm{a}$ & $2,04 \mathrm{D} \mathrm{a}$ & $0,49 \mathrm{~A} \mathrm{a}$ \\
& Papel & $84 \mathrm{C} \mathrm{a}$ & $2,48 \mathrm{BC} \mathrm{b}$ & $0,40 \mathrm{C} \mathrm{a}$ \\
& Algodão & $86 \mathrm{~B} \mathrm{a}$ & $2,85 \mathrm{~B} \mathrm{a}$ & $0,36 \mathrm{C} \mathrm{b}$ \\
& Plástico & $80 \mathrm{~B} \mathrm{a}$ & $2,59 \mathrm{BC}$ ab & $0,39 \mathrm{ab}$ \\
\hline
\end{tabular}
* Letras maiúsculas comparam médias dentro de um mesmo tipo de embalagem e entre temperaturas distintas e letras
minúsculas comparam médias entre tipos de embalagem dentro de uma mesma temperatura.

de T. aurea ao início e ao final do período de armazenamento foi de $12,53 \%$ e $14,17 \%$, respectivamente. Aos 30 dias não se realizou o teste de viabilidade das sementes a $35^{\circ} \mathrm{C}$, pois a mesma já tinha sido verificada a $25^{\circ} \mathrm{C}$, no teste de fotoblastismo, e apresentaram germinabilidade de $98 \%$ na embalagem de papel, $95 \%$ na de algodão e $88 \%$ na de plástico (Tab. 1). Verificou-se que as percentagens de germinação aos 60 e 90 dias de armazenamento não diferiram significativamente, nos diferentes tipos de acondicionamento (Tab. 3). No entanto, aos 120 dias nos três tipos de embalagens utilizados, houve redução significativa na percentagem de germinação.

Levando-se em conta que o objetivo básico do armazenamento é manter o percentual de germinação ao final do período o mais próximo ao do inicial, $\mathrm{o}$ acondicionamento das sementes em sacos de plástico foi o tratamento que mais se aproximou do desejado. Pois, embora não havendo diferenças significativas entre as embalagens empregadas, durante todo o período experimental, a redução na percentagem de germinação das sementes acondicionadas na embalagem de plástico foi de apenas $8 \%$, enquanto que nas embalagens de papel e algodão foram de $13 \%$ e $15 \%$, respectivamente, do início ao final do período de armazenamento.

Deste modo observou-se que a capacidade germinativa das sementes armazenadas em câmara fria e seca foi mantida por 120 dias. A qualidade fisiológica das sementes não foi afetada pela permeabilidade das embalagens. Esses resultados concordam com os obtidos por Souza et al. $(1980 \mathrm{a}, \mathrm{b})$ para outras espécies características da região semi-árida nordestina assim discriminadas: Anadenanthera macrocarpa, Tabebuia impetiginosa Mart., Pseudobombax simpliciflolium A. Robyns e Astronium urundeuva Engl., armazenadas em câmara fria $\left(8^{\circ} \mathrm{C}\right.$ e $50 \%$ UR) e acondicionadas em sacos de 
Tabela 3. Percentagem e velocidade média de germinação em sementes de Tabebuia aurea (Manso) Benth. \& Hook. f. ex. S. Moore, a $35^{\circ} \mathrm{C}$ e ausência de luz, armazenadas por 60,90 e 120 dias, em câmara fria e seca $\left(15^{\circ} \mathrm{C} ; 40 \%\right.$ U.R.), em sacos de papel, algodão e plástico. ( $\mathrm{G}=$ Germinação; $\overline{\mathrm{v}}=$ velocidade média em dias).

\begin{tabular}{|c|c|c|c|c|c|c|}
\hline \multirow{3}{*}{ Tipo de embalagem } & \multicolumn{6}{|c|}{ Tempo (dias) } \\
\hline & \multicolumn{2}{|c|}{60} & \multicolumn{2}{|c|}{90} & \multicolumn{2}{|c|}{120} \\
\hline & $\mathrm{G}(\%)$ & $\overline{\mathrm{V}}\left(\mathrm{d}^{-1}\right)$ & $\mathrm{G}(\%)$ & $\overline{\mathrm{V}}\left(\mathrm{d}^{-1}\right)$ & $\mathrm{G}(\%)$ & $\overline{\mathrm{v}}\left(\mathrm{d}^{-1}\right)$ \\
\hline Papel & $97 \mathrm{~A} \mathrm{a}$ & $0,50 \mathrm{~A} \mathrm{a}$ & $94 \mathrm{~A} \mathrm{a}$ & $0,48 \mathrm{~A} \mathrm{a}$ & $84 \mathrm{~B} \mathrm{a}$ & $0,45 \mathrm{~A} \mathrm{~b}$ \\
\hline Algodão & $97 \mathrm{~A} \mathrm{a}$ & $0,49 \mathrm{~A}$ a & $96 \mathrm{~A} \mathrm{a}$ & $0,49 \mathrm{~A}$ a & $82 \mathrm{~B} \mathrm{a}$ & $0,47 \mathrm{~A}$ a \\
\hline Plástico & $97 \mathrm{~A} \mathrm{a}$ & $0,49 \mathrm{~A} \mathrm{a}$ & $92 \mathrm{~A} \mathrm{a}$ & $0,48 \mathrm{~A} \mathrm{a}$ & $89 \mathrm{~B} \mathrm{a}$ & $0,45 \mathrm{~A} \mathrm{~b}$ \\
\hline
\end{tabular}

* Letras maiúsculas comparam os diferentes períodos de armazenamento dentro de uma mesma embalagem e letras minúsculas comparam os diferentes tipos de embalagens em um mesmo período

algodão e polietileno. Silva et al. (2001), trabalhando com sementes de Tabebuia heterophylla (A.P. Candolle) Britton, em São Paulo, evidenciaram a eficiência da baixa temperatura na conservação das sementes em embalagem impermeável obtendo após 489 dias $86 \%$ de germinação.

A velocidade média de germinação não se alterou aos 60 e 90 dias de armazenamento, no entanto, aos 120 dias, houve diferença significativa nas sementes mantidas em sacos de algodão, com valores superiores, quando comparadas com as embalagens de papel e plástico (Tab. 3). Essa redução na velocidade de germinação pode ser atribuída à diminuição no vigor das sementes, pois segundo a literatura as sementes do gênero Tabebuia perdem a viabilidade rapidamente (Pinto et al. 1986). Porém, de maneira geral, a velocidade de germinação dessa espécie foi alta dos 60 aos 120 dias, variando de 0,45 a 0,50 d $\mathrm{d}^{-1}$. Embora havendo pequeno aumento no teor de umidade no final do período de armazenamento, aparentemente não existe relação com a pequena redução no vigor das sementes.

Efeito do tempo e do tipo de embalagem de armazenamento na embebição - As sementes de T. aurea apresentaram rápida velocidade de embebição nas primeiras quatro horas, sendo o aumento superior a $100 \%$ em todos os tipos de embalagens, exceção para as sementes acondicionadas em sacos de algodão aos 120 dias, que ultrapassou esse limite após seis horas de embebição (Tab. 4).

Neiva (1997), estudando a velocidade de embebição de Caesalpinia pyramidalis Tul., Caesalpinia ferrea Mart. ex Tul., Senna martiana (Benth.) Irwin \& Barneby e Senna spectabilis (D.C.) Irwin \& Barneby, espécies ocorrentes na caatinga, armazenadas por seis meses em câmara fria $\left(15^{\circ} \mathrm{C}\right.$ e $40 \%$ de U.R.), nas mesmas condições aqui empregadas, verificou que após $12 \mathrm{~h}$ de embebição, apenas Caesalpinia pyramidalis atingiu $61,4 \%$ de aumento no peso e as demais espécies não ultrapassaram $30 \%$.

A velocidade de embebição das sementes armazenadas por 30 dias não diferiu durante o período de embebição nos três tipos de embalagens, com exceção às $12 \mathrm{~h}$ de embebição em saco de algodão, cuja velocidade foi significativamente menor em relação aos demais tipos de embalagens. Aos 60 dias a velocidade de embebição das sementes acondicionadas em sacos de papel e algodão apresentaram valores significativamente inferiores a partir das $8 \mathrm{~h}$ de embebição, porém aos 120 dias, a velocidade de embebição foi significativamente menor para as sementes provenientes de sacos de algodão. Isso provavelmente está relacionado ao fato do algodão ser o mais poroso dos materiais 
Tabela 4. Velocidade de embebição (\%/h) em sementes de Tabebuia aurea (Manso) Benth. \& Hook. f. ex. S. Moore, armazenadas por 30, 60 e 120 dias em câmara fria e seca $\left(15^{\circ} \mathrm{C} ; 40 \%\right.$ U.R.), em sacos de papel, algodão e plástico.

\begin{tabular}{|c|c|c|c|c|c|c|c|}
\hline \multirow{2}{*}{$\begin{array}{c}\text { Armazenamento } \\
\text { (dias) }\end{array}$} & \multirow{2}{*}{$\begin{array}{c}\text { Tipo de } \\
\text { embalagem }\end{array}$} & \multicolumn{6}{|c|}{ Tempo de embebição (horas) } \\
\hline & & 2 & 4 & 6 & 8 & 10 & 12 \\
\hline \multirow[t]{3}{*}{30} & Papel & $85,05 \mathrm{Aa}$ & $110,27 \mathrm{Aa}$ & $132,31 \mathrm{Aa}$ & $152,96 \mathrm{Aa}$ & $167,00 \mathrm{Aa}$ & $176,05 \mathrm{Aa}$ \\
\hline & Algodão & $82,13 \mathrm{Aa}$ & $104,79 \mathrm{Aa}$ & $124,76 \mathrm{Aa}$ & $142,47 \mathrm{Aa}$ & $156,48 \mathrm{Aa}$ & $163,94 \mathrm{Ab}$ \\
\hline & Plástico & $86,92 \mathrm{Aa}$ & $112,38 \mathrm{Aa}$ & $134,51 \mathrm{Aa}$ & $153,09 \mathrm{Aa}$ & $163,98 \mathrm{Aa}$ & $173,19 \mathrm{Aa}$ \\
\hline \multirow[t]{3}{*}{60} & Papel & $74,56 \mathrm{Ba}$ & $107,49 \mathrm{Aa}$ & $123,47 \mathrm{Ba}$ & $141,84 \mathrm{Bb}$ & $153,75 \mathrm{Bb}$ & $161,96 \mathrm{Bb}$ \\
\hline & Algodão & $80,45 \mathrm{Aa}$ & $100,99 \mathrm{Aa}$ & $121,48 \mathrm{Aa}$ & $135,68 \mathrm{Ab}$ & $145,85 \mathrm{Ab}$ & $155,06 \mathrm{Ab}$ \\
\hline & Plástico & $83,93 \mathrm{Aa}$ & $109,72 \mathrm{Aa}$ & $129,89 \mathrm{Aa}$ & $153,69 \mathrm{Aa}$ & $165,89 \mathrm{Aa}$ & $175,80 \mathrm{Aa}$ \\
\hline \multirow[t]{3}{*}{120} & Papel & $73,60 \mathrm{Bab}$ & $106,35 \mathrm{Aa}$ & $128,40 \mathrm{ABa}$ & $145,66 \mathrm{ABa}$ & $161,42 \mathrm{Aa}$ & $173,86 \mathrm{Aa}$ \\
\hline & Algodão & $66,34 \mathrm{Bb}$ & $89,65 \mathrm{Bb}$ & $112,00 \mathrm{Ab}$ & $130,07 \mathrm{Ab}$ & $147,70 \mathrm{Ab}$ & $161,10 \mathrm{Ab}$ \\
\hline & Plástico & $82,27 \mathrm{Aa}$ & $110,10 \mathrm{Aa}$ & $130,67 \mathrm{Aa}$ & $147,71 \mathrm{Aa}$ & $159,32 \mathrm{Aa}$ & $169,07 \mathrm{Aa}$ \\
\hline
\end{tabular}

* Letras maiúsculas comparam porcentagem de embebição nos diferentes períodos de armazenamento dentro de um mesmo tipo de embalagem e letras minúsculas comparam a porcentagem de embebição nos diferentes tipos de embalagem em um mesmo período

utilizados, permitindo portanto, maior troca do vapor de água com o ambiente de armazenamento.

Diante do exposto verificou-se que as embalagens utilizadas no armazenamento não afetaram significativamente as variáveis estudadas. A espécie em estudo classificouse como fotoblástica neutra à $25^{\circ} \mathrm{C}$, com percentagem média de germinação variando de 88 a $98 \%$, no período de 10 dias. A temperatura ótima de germinação foi de $35^{\circ} \mathrm{C}$, a mínima de $20^{\circ} \mathrm{C}$ e a máxima de $40^{\circ} \mathrm{C}$, na ausência de luz. As embalagens utilizadas no armazenamento mantiveram a viabilidade das sementes até os 120 dias, com altos percentuais, variando de 88 a $97 \%$ de germinação. As sementes apresentaram velocidade de embebição rápida atingindo $100 \%$ a partir de 4 h de embebição.

\section{Agradecimento}

Aos funcionários do Setor de Sementes da Empresa Pernambucana de Pesquisa Agropecuária (IPA), pelo armazenamento das sementes.

\section{Referências bibliográficas}

Arrigoni-Blank, M. F.; Carvalho, D. A.; Alvarenga, A. A.; Laura, V. A. \& Blank, A. F. 1997. Fenologia e germinação de guabiroba (Camponanesia pubescens (DC.) Berg.): espécie de Cerrado. Ciência e Agrotecnologia 21(2): 237-241.

Ayres, M. \& Ayres-Júnior, M. 1998. BioEstat - Aplicações estatísticas nas áreas das ciências biológicas e médicas. Sociedade Civil Mamirauá, Manaus.

Barbosa, D. C. A. 1980. Estudos ecofisiológicos em Anadenanthera macrocarpa (Benth.) Brenan. Aspectos da germinação e do crescimento. Tese de Doutorado. Universidade de São Paulo, São Paulo.

Barros, L. M. \& Barbosa, D. C. A. 1991. Quebra de dormência em sementes de Acacia farnesiana (L.) Willd. Leguminosae-Mimosoideae. Biologica Brasilica 3(2): 156-164.

Bewley, J. D. \& Black, M. 1994. Seeds physiology of development and germination. Plenum Press, New York.

Brasil. 1992. Regras para análise de sementes. Ministério da Agricultura e da Reforma Agrária, Brasília.

Carvalho, N. M. \& Nakagawa, J. 1988. Sementes: ciência tecnologia e produção. $3^{\mathrm{a}}$ ed. Fundação Cargil, Campinas.

Casteleti, C. H. M.; Santos, A. M. M.; Tabarelli, M. \& Silva, J. M. C. 2003. Quanto ainda resta da Caatinga? Uma estimativa preliminar. Pp. 719-734. In: L. R. Leal; M. Tabarelli \& J. M. C. Silva. Ecologia e conservação da Caatinga. Editora da UFPE, Recife. 
Delouche, J. C.; Matthes, R. K.; Dougherty, G. M. \& Boyd, A. H. 1973. Storage of seed in sub-tropical and tropical regions. Seed Science and Tecnology 1(3): 671-700.

Felippe, G. M. \& Silva, J. C. S. 1984. Estudos de germinação em espécies do cerrado. Revista Brasileira de Botânica 7(2): 157-163.

Joly, C. A. \& Felippe, G. M. 1979. Dormência das sementes de Rapanea guianensis Aubl. Revista Brasileira de Botânica 2(1): 1-6.

Joly, C. A.; Felippe, G. M.; Dietrich, S. M. C. \& CamposTakaki, G. M. 1980. Physiology of germination and seed gel analysis in two populations of Magonia pubescens St. Hil. Revista Brasileira de Botânica 3(1/2): 1-9.

Kigel, J. \& Galili, G. 1995. Seed development and germination. Marcel Dekker Inc, New York.

Labouriau, L. G. 1983. A germinação das sementes. Secretaria Geral da Organização dos Estados Americanos, Washington.

Labouriau, L. G. \& Pacheco, A. 1978. On the frequency of isothermal germination in seeds of Dolichos biflorus L. Plant \& Cell Physiology 19(3): 507-512.

Labouriau, L. G. \& Valadares, M. B. 1976. On the germination of seeds of Calotropis procera. Anais da Academia Brasileira de Ciências 48: $174-186$.

Larcher, W. 2000. Ecofisiologia Vegetal. Rima Artes e Textos, São Carlos.

Lorenzi, H. 1992. Árvores brasileiras: manual de identificação e cultivo de plantas arbóreas nativas do Brasil. Ed. Plantarum, Nova Odessa.

Mayer A. M. \& Poljakoff-Mayber A. 1979. The germination of seeds. Pergamon Press, Oxford.

Melhem, T. S. 1975. Fisiologia da germinação das sementes de Dipteryx alata Vog. (LeguminosaeLotoideae). Hoehnea 5: 59-90.

Melo, J. T.; Ribeiro, J. F. \& Lima, V. L. G. F. 1979. Germinação de sementes de algumas espécies arbóreas nativas do cerrado. Revista Brasileira de Sementes 1(2): 8-12.

Nascimento, M. P. S. C. B. \& Oliveira, M. E. A. 1999. Quebra de dormência de sementes de quatro leguminosas arbóreas. Acta Botanica Brasilica 13(2): 129-137.
Neiva, M. S. M. 1997. Estrutura dos tegumentos, germinação e aspectos bioquímicos das sementes de quatro espécies de Leguminosae (Caesalpinioidea), ocorrentes numa área de caatinga. Dissertação de Mestrado. Universidade Federal de Pernambuco, Recife.

Pinto, M.M.; Sader, R. \& Barbosa, J. M. 1986. Influência do tempo de secagem e do armazenamento sobre a viabilidade das sementes de ipêrosa. Revista Brasileira de Sementes 8(1): 37-47.

Popinigis, F. 1985. Fisiologia das sementes. Ministério da Agricultura - AGIPLAN, Brasília.

Queiroz, L. P. 1999. Leguminosas de caatinga, espécies com potencial forrageiro. Pp. 63-75. In: F D. Araújo; H. D. V. Prendergast \& S. J. Mayo (eds.). Plantas do Nordeste. Anais do I Workshop Geral. Royal Botanic Gardens, Kew.

Silva, J. C. S. \& Felippe, G. M. 1986. Germination of Stylosanthes macrocephala. Revista Brasileira de Botânica 9(2): 263-268.

Silva, A. da; Figliolia, M. B.; Aguiar, I. B. \& Perecin, D. 2001. Liofilização e armazenamento de sementes de ipê-rosa (Tabebuia heterophylla (A.P. Cabdolle) Britton) - Bignoniaceae. Revista Brasileira de Sementes 23(1): 252-259.

Souza, S. M.; Pires, I. E. \& Lima, P. C. F. 1980a. Influência da embalagem e condições de armazenamento na longevidade de sementes florestais. Pp. 15-24. In: Pesquisa Florestal no Nordeste Semi-árido: sementes e mudas. Boletim de Pesquisa n. 2, EMBRAPA - CPTSA, Petrolina.

Souza, S. M.; Pires, I. E. \& Lima, P. C. F. 1980b. Efeito do tipo de embalagem e condições de armazenamento na preservação de sementes de aroeira (Astronium urundeuva) Engl. Pp. 25-30. In: Pesquisa Florestal no Nordeste Semi-árido: sementes e mudas. Boletim de Pesquisa n. 2, EMBRAPA - CPTSA, Petrolina.

Tigre, C. D. 1970. Silvicultura para as matas xerófilas. Publ. 243. MINTER / DNOCS, Fortaleza.

Townsend, C. E. \& McGinnies, W. J. 1972. Mechanical scarification of cicer milkvetch (Astragalus cicer L.) seed. Crop Science 12(4): 392-394.

Viana, A. M. \& Felippe, G. M. 1986. Efeitos da luz e da temperatura na germinação de sementes de Dioscorea composita. Revista Brasileira de Botânica 9(2): 109-115. 